\title{
HLA-G14bp ins/del polymorphism and post-transplant weight gain in kidney transplantation: potential implications beyond tolerance
}

Daniela Piancatelli ${ }^{1 *}$, Daniela Maccarone ${ }^{2}$, Alessia Colanardi $^{1}$, Pierluigi Sebastiani ${ }^{1}$, Katia Clemente $^{3}$, Samuele lesari ${ }^{4,5}$, Quirino Lai ${ }^{6}$ and Francesco Pisani ${ }^{3,5}$

\begin{abstract}
Background: Human leukocyte antigen (HLA)-G is a non-classical HLA molecule with immunomodulant and immunosuppressive functions, involved in transplantation tolerance. HLA-G14bp ins/del polymorphism in exon 8 has been associated with allograft rejection and kidney transplant outcome, with controversial results. We investigated associations of HLA-G14bp ins/del polymorphism on onset of some of the main post-transplant risk factors, like excess body weight, lipid abnormalities, increased fasting plasma glucose. Polymorphisms of cytokines with both immunosuppressive and metabolic effects were also assessed for comparisons and associated analysis.

Methods: The present study involved kidney transplant recipients $(n=173)$ in which body mass index, cholesterol, triglycerides, fasting plasma glucose were registered in the first years after transplantation and analyzed in association with genotypes. Presence of hypertension and smoking habits, demographic, transplant-related and therapeutic data of patients were also recorded. Polymerase chain reaction, sequence-specific primer amplification and Taqman allelic discrimination techniques were used for genotyping of HLA-G14bp ins/del, interleukin (IL)10(-1082G $>A,-819 T>C,-592 A>C)$, transforming growth factor- $\beta(+869 T>C,+915 C>G), I L-6(-174 G>C)$, tumor necrosis factor-a $(-308 \mathrm{G}>\mathrm{A})$ and IL-18(-137G $>\mathrm{C},-607 \mathrm{C}>\mathrm{A})$. Effects of genotypes on clinical markers at each time point (pre-transplant and 1 to 5 years after transplant) were analyzed using a repeated-measures general linear model analysis; adjustment for potential confounders was performed.

Results: Results showed that HLA-G14bp ins/ins was significantly associated with obesity, in particular after transplantation ( 3 years, $p=0.002, \mathrm{OR}=4.48,95 \% \mathrm{Cl}: 1.76-11.41$ ). Post-transplant body mass index was significantly increased in HLA-G14bp ins/ins carriers ( 3 and 4 years, $p=0.033$ and $p=0.044$ ); effects of HLA-G14bp genotypes on post-transplant BMI were confirmed by using repeated-measures analysis and after controlling for confounding variables. Cytokine genotypes did not associate with the examined factors.

(Continued on next page)
\end{abstract}

\footnotetext{
* Correspondence: daniela.piancatelli@enr.it

${ }^{1}$ National Research Council (CNR) - Institute of Translational Pharmacology

(IFT), Via Carducci, 32, 67100 L'Aquila, Italy

Full list of author information is available at the end of the article
}

(c) The Author(s). 2020 Open Access This article is licensed under a Creative Commons Attribution 4.0 International License, which permits use, sharing, adaptation, distribution and reproduction in any medium or format, as long as you give appropriate credit to the original author(s) and the source, provide a link to the Creative Commons licence, and indicate if changes were made. The images or other third party material in this article are included in the article's Creative Commons licence, unless indicated otherwise in a credit line to the material. If material is not included in the article's Creative Commons licence and your intended use is not permitted by statutory regulation or exceeds the permitted use, you will need to obtain permission directly from the copyright holder. To view a copy of this licence, visit http://creativecommons.org/licenses/by/4.0/ The Creative Commons Public Domain Dedication waiver (http://creativecommons.org/publicdomain/zero/1.0/) applies to the data made available in this article, unless otherwise stated in a credit line to the data. 
(Continued from previous page)

Conclusions: The study of transplanted patients allowed to evidence a potential relationship between post-

transplant weight gain and HLA-G14bp ins/del polymorphism, previously involved in rejection for its

immunosuppressive/tolerogenic activity. This novel association could widen the knowledge of the role and

functions of HLA-G molecules in diseases and transplantation.

Keywords: HLA-G, Gene polymorphism, Kidney transplant, Obesity, Immunogenetics

\section{Background}

Immunogenetic polymorphisms of molecules involved in allograft rejection and tolerance could have an impact on pathogenic mechanisms, which promote or prevent risk for post-transplant cardiovascular and metabolic morbidity. It is the case of some cytokines, which were extensively investigated in both transplanted patients and cardiovascular and metabolic diseases.

Obesity, dyslipidemia, type 2 diabetes mellitus (T2DM) and arterial hypertension are known post-transplant risk factors for cardiovascular diseases and allograft dysfunction: they are involved in allograft survival, metabolic syndrome, and increased post-transplant cardiovascular complications and mortality [1].

Body mass index (BMI) is the most common measure of obesity. Increased BMI is now a common finding in transplant candidates, more than in the past. Increased BMI (in particular over $30 \mathrm{~kg} / \mathrm{m}^{2}$ ) was recently confirmed as a predictor of both early (acute rejection and delayed graft function) and long-term adverse kidney transplant outcome in a large study [2]. Post-transplant weight gain affects both normal-weight and overweight/ obese patients (about $9-14 \mathrm{~kg}$ in the first year after transplantation and from $11 \%$ in the first year to $15 \%$ over 5 years) [3].

Both cardiovascular, metabolic, infectious diseases and malignancies are promoted as a part of adverse effects of post-transplant immunosuppressive medications, together with pre-transplant and general risk factors. Interactions between immune and metabolic mechanisms are known [4]; relationships exist between obesity, inflammation and decreased immunological tolerance, as indicated by studies in allergic, infectious diseases and cancer [5-7].

In human conditions such as obesity, a low-grade inflammation with increased levels of pro-inflammatory markers is present; some inflammatory cytokines (i.e., interleukin (IL)-6, IL-18) are involved in BMI increase, metabolic and cardiovascular diseases [8-10] and antiinflammatory interventions can, at least in part, counteract metabolic dysfunctions.

Both the delayed immune response directed towards the transplanted kidney and injuries directed towards different tissues in recipients are mediated by molecules that show a certain grade of genetic variability.
Functional polymorphisms of genes encoding immunosuppressive and tolerogenic molecules could be potentially predictive of post-transplant risk. Human Leukocyte Antigen (HLA)-G is a non-classical HLA molecule with immunomodulant and immunosuppressive functions. The most common HLA-G polymorphism consists of an insertion/deletion (ins/del) of 14 base pairs (bp) in exon 8 that induces changes of messenger ribonucleic acid (mRNA) stability, and protein expression [11]. Transplantation is a condition that could modify HLA-G expression. In kidney transplantation, HLA$G$ expression could be protective, because it inhibits alloreactive response towards the graft [12]. However, associations between HLA-G14bp genotypes and rejection were investigated, with inconclusive results [13-15]: an association of HLA-G14bp ins/ins genotype with acute rejection was found, although in a limited number of patients [13] and recipients with acute rejection were found to have lower soluble HLA-G (sHLA-G) levels [15]. Instead, HLA-G mRNA in graft biopsies was significantly higher in acute rejection, in comparison with patients with no rejection [16].

HLA-G expression can be modulated by other cytokines involved in proinflammatory, profibrotic and alloreactive responses. An example is represented by IL-10, which shares the anti-inflammatory properties and mechanisms of induction of tolerance with HLA-G. A previous study suggested an IL-10/HLA-G autocrine loop in physiological conditions, as an increase of IL-10 production from lipopolysaccharides (LPS)-activated peripheral blood mononuclear cells (PBMC) was preceded by sHLA-G release [17]. Recently, a role of HLAG14bp polymorphism in vascular health has been suggested in kidney trasplant recipients [18].

Transplant recipients, generally being well-monitored and compliant patients during the first post-transplant years, represent a model for studying therapy-induced variations of risk factors and their interaction with some gene variants.

Based on these observations, our attention was focused on HLA-G14bp ins/del and other polymorphisms of cytokines involved in tolerance, inflammation and/or metabolic regulation (IL-10, Transforming Growth Factor (TGF)- $\beta$, IL-6, Tumor Necrosis Factor (TNF)- $\alpha$, and IL-18); effects of genotypes on post-transplant weight 
gain and alterations of other risk factors for posttransplant complications were evaluated in kidney transplant recipients.

\section{Methods}

\section{Patients}

DNA samples were obtained from 173 Italian kidney transplanted patients from deceased donors (117 men and 56 women, mainly coming from Central Italy), regularly undergoing post-transplant follow up in the Unit of General Surgery and Transplantation of S. Salvatore Hospital of L'Aquila, Italy, where they were transplanted (between 2001 to 2010, except 2 patients transplanted elsewhere). The minimum follow-up was 36 months. Exclusion criteria were non-Caucasian race, age less than 18 years, pregnancy, severe diseases (malignancies or other diseases with poor prognosis in the short term, sepsis), primary non-function, graft loss within the first 3 years, irregular post-transplant monitoring or performed elsewhere, re-transplantation and transplantation from living donors.

Clinical features of patients and recorded parameters are reported in Table 1.

In addition, presence of hypertension $(\geq 140 / 90 \mathrm{mmHg}$ or use of antihypertensive drugs), the onset of T2DM, dyslipidemia (cholesterol $>200 \mathrm{mg} / \mathrm{dl}$ and/or triglycerides $>150 \mathrm{mg} / \mathrm{dl}$, use of antidyslipidemic drugs), other pharmacological treatments (in addition to immunosuppressive therapy) and smoking habits were recorded.

All patients received induction therapy with basiliximab (anti-CD25 monoclonal antibody) and corticosteroids. Standard maintenance immunosuppressive regimens consisted of 1) calcineurin inhibitors (cyclosporine or tacrolimus), corticosteroids and inhibitors of purine synthesis (mycophenolate-mofetil or mycophenolic acid) (about $84 \%$ of patients), or 2) cyclosporine, corticosteroids and mammalian target of rapamycin inhibitors (mTORi, everolimus) (16\%). Written informed consent was obtained from all subjects, investigations were carried out by the principles of the Declaration of Helsinki, and the study was approved by the local ethics committee (study n. 50/ 2008).

\section{Biochemical parameters}

BMI, cholesterol, triglycerides, fasting plasma glucose, and creatinine were recorded before (i.e., baseline, at the time of the last half-yearly follow-up before the transplant) and after transplantation (each year, at annual follow-up, up to 5 years) and analyzed for associations with gene polymorphisms.

\section{DNA extraction and HLA-G14bp ins/del polymorphism}

For each patient, genomic DNA was obtained from peripheral blood using commercial kits (QIAamp DNA
Table 1 Demographic and clinical characteristics of kidney transplant recipients $(n=173)$

\begin{tabular}{|c|c|}
\hline Gender ( $n, \%)$ & $\begin{array}{l}\text { M: } 117(67.6 \%) \\
\text { F: } 56(32.3 \%)\end{array}$ \\
\hline Age at transplant (years, mean $\pm S D$ ) & $\begin{array}{l}46.77 \pm 10.60 \\
\text { (range } 24-68)\end{array}$ \\
\hline Dialysis mode (\%) & $\begin{array}{l}\text { 19\% peritoneal, } \\
81 \% \text { hemodialysis }\end{array}$ \\
\hline Time on dialysis (years, mean \pm SD) & $\begin{array}{l}2.81 \pm 2.97 \\
(\text { range }<1-26)\end{array}$ \\
\hline \multicolumn{2}{|l|}{ Immunosuppressive therapy: } \\
\hline $\begin{array}{l}\text { - Calcineurin inhibitors (CsA or TAC), steroids, } \\
\text { purine synthesis inhibitors (\%) }\end{array}$ & $84 \%$ \\
\hline $\begin{array}{l}\text { - mTOR inhibitors, steroids, purine synthesis } \\
\text { inhibitors (\%) }\end{array}$ & $16 \%$ \\
\hline $\begin{array}{l}\text { Pre-transplant impaired/diabetic } \\
\text { fasting blood glucose }(\%)\end{array}$ & $13 \%$ \\
\hline Cold ischemia time (hours, mean \pm SD) & $\begin{array}{l}11.45 \pm 3.31 \\
\text { (range } 4.2-21.6 \text { ) }\end{array}$ \\
\hline Recipients with acute rejection episodes (n, \%) & $24(13.9 \%)$ \\
\hline 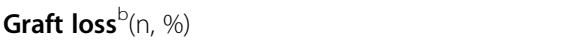 & $4(2.3 \%)$ \\
\hline \multicolumn{2}{|l|}{ Primary nephropathy } \\
\hline Glomerulonephritis ${ }^{c}$ & $73(42 \%)$ \\
\hline Polycystic kidney disease & $33(19 \%)$ \\
\hline Nephroangiosclerosis & $6(4 \%)$ \\
\hline Hypertensive/vascular nephropathies & $19(11 \%)$ \\
\hline Chronic pyelonephritis & $8(5 \%)$ \\
\hline Not determined & $16(9 \%)$ \\
\hline Other nephropathies $^{d}$ & $18(10 \%)$ \\
\hline
\end{tabular}

afasting plasma glucose: impaired: $111-125 \mathrm{mg} / \mathrm{dl}$; diabetic: $>125 \mathrm{mg} / \mathrm{dl}(\mathrm{WHO})$ ${ }^{b}$ four cases of graft loss during the 5 -years follow up (over 3 years post-transplant) 'chronic, membranous, focal glomerulosclerosis, rapidly progressive, LES, Goodpasture, IRC post-partum, diabetic, Alport syndrome, IgA nephropathy ${ }^{d}$ congenital, amyloid, neoplastic, post-traumatic, obstructive, hemolytic-uremic syndrome, contracted kidney, interstitial nephropathy

blood kit, Qiagen, Hilden, Germany) and stored frozen at $-20^{\circ} \mathrm{C}$ until use. DNA concentration and purity were spectrophotometrically assessed.

The HLA-G14bp ins/del polymorphism in exon 8 was detected as previously described [19]. In brief, genomic DNA (100 ng) was amplified in a $25 \mu \mathrm{l}$ reaction, using specific primers; polymerase chain reaction $(\mathrm{PCR})$ products, $210 \mathrm{bp}$ (del) and/or $224 \mathrm{bp}$ (ins), were visualized by electrophoresis on a $4 \%$ agarose gel (NuSieve GTG agarose) containing ethidium bromide.

IL-10, TGF- $\beta$, IL-6, TNF- $\alpha$, and IL-18 gene polymorphisms Cytokine gene polymorphisms were detected on genomic DNA. IL-10 $(-1082 \mathrm{G}>\mathrm{A}),(-819 \mathrm{~T}>\mathrm{C})$ and $(-592 \mathrm{~A}>\mathrm{C})$ (promoter region, haplotypes GCC, ACC and ATA), TGF $-\beta(+869 \mathrm{~T}>\mathrm{C})$ and $(+915 \mathrm{C}>\mathrm{G})$, (codons 10 and 25 , 
exon 1), IL-6(-174G > C) and TNF- $\alpha(-308 G>A)$ genotypes were assessed using a polymerase chain reactionsequence-specific primers (PCR-SSP) method, according to manufacturer instructions (Cytokine genotyping Primer Pack, Pcytgen, One Lambda, Inc., CA, USA). In each PCR, internal control was included; PCR products were visualized on a $2 \%$ agarose gel electrophoresis containing ethidium bromide $(0.5 \mathrm{mg} / \mathrm{ml})$. A DNA ladder was present in each gel, and the molecular weight of the PCR products were checked. Allele, genotype, and haplotype frequencies were reported; based on previous data on functional evidence, genotypes, and haplotype combinations were also defined as high, intermediate and low cytokine producers [20].

IL-18 $(-137 \mathrm{G}>\mathrm{C}) \quad(\mathrm{rs} 187238) \quad$ and $\quad(-607 \mathrm{C}>\mathrm{A})$ (rs1946518) were genotyped using Taqman allelic discrimination assays (Applied Biosystems, CA, USA) on a StepOne Real-Time PCR system.

An Italian population sample of randomly-selected unrelated donors was used as a reference for comparisons of allele/genotype/haplotype frequencies.

\section{Statistical analysis}

Allele, genotype, and haplotype frequencies were calculated. Chi-squared test was used for the analysis of associations between gene polymorphisms and clinical variables of post-transplant risk. Odds ratio (OR) and its 95\% confidence interval $(\mathrm{CI})$ were estimated. Comparisons between groups and correlation between variables were examined by parametric (t-test/paired $t$ test, Pearson's correlation) and non-parametric tests (Mann Whitney U test/Wilcoxon, Spearman's correlation coefficients), as appropriate. To explore genotype effects and interactions, changes in clinical markers at each time point (pre-transplant and 1 to 5 years after transplant, within-subject factor) between genotypes (between-subject factor) were analyzed using an ANOVA for repeated measures; adjustment for potential confounders was performed. A Bonferroni post hoc test was used to assess the significance level for differences between the individual time points.

Analyses were conducted using an SPSS statistical package (SPSS Inc., Chicago, IL) and Arlequin software [21]. Two-tailed $p$ values $<0.05$ were considered statistically significant. All tests were two-sided.

\section{Results}

\section{Patients}

Clinical features of transplanted patients $(n=173)$ are reported in Table 1.

All patients were not pre-emptive and not retransplanted recipients with up to a five-year follow up recorded data, except three patients who had graft loss after a three-year follow-up. Mean age at transplant was $46.77 \pm 10.60$ years.
Variations of pre/post- transplant blood triglycerides, total cholesterol, fasting plasma glucose, BMI and creatinine are reported in Fig. 1, where the trend for total patients and subsets treated for dyslipidemia or diabetes is reported. Total cholesterol significantly increased after 1 year (total patients, pre-transplant, $174.07 \pm 41.48 \mathrm{mg}$ / dl; after transplant, 1 year: $199.16 \pm 38.69 \mathrm{mg} / \mathrm{dl}, \quad p<$ 0.001 ), while triglycerides and creatinine were significantly reduced after transplantation (total patients, triglycerides, from $175.90 \pm 91.31 \mathrm{mg} / \mathrm{dl}$ pre-transplant to $139.95 \pm 59.65 \mathrm{mg} / \mathrm{dl}$ at 3 years and $131.68 \pm 53.63 \mathrm{mg} / \mathrm{dl}$ at 5 years post-transplant, $p<0.01$; creatinine: from $2.10 \pm 0.96 \mathrm{mg} / \mathrm{dl}$ pre-transplant to $1.46 \pm 0.49$ at 3 years and $1.48 \pm 0.64 \mathrm{mg} / \mathrm{dl}$ at 5 years post-transplant, $p<$ $0.001)$. BMI significantly increased over time after transplantation (total patients, from $24.75 \pm 4.02 \mathrm{~kg} / \mathrm{m}^{2}$ pretransplant to $25.75 \pm 4.00 \mathrm{~kg} / \mathrm{m}^{2} 3$ years and $26.02 \pm 4.26$ $\mathrm{kg} / \mathrm{m}^{2} 5$ years post-transplant, $\left.p<0.005\right)$. In particular, post hoc test with Bonferroni correction showed a significantly increased BMI from pre- to post-transplant (1-5 years, $p<0.005)$ and between one-two years and five years assessments after transplantation $(p=0.016$ and $p=0.043$, respectively), as compared with pretransplant BMI. Post-transplant BMI was correlated with age at transplant $(p<0.006)$, pre-transplant BMI $(p<$ $0.001)$ and creatinine $(p<0.005)$.

\section{Obesity, dyslipidemia, diabetes mellitus}

Based on BMI values, patients were grouped into normal range weight $\left(\mathrm{BMI}<25 \mathrm{~kg} / \mathrm{m}^{2}\right)$, overweight (BMI $\left.25-29.99 \mathrm{~kg} / \mathrm{m}^{2}\right)$ and obese $\left(\mathrm{BMI} \geq 30 \mathrm{~kg} / \mathrm{m}^{2}\right)$, according to World Health Organization (WHO) criteria [22].

Prevalence of obesity ranged from 11\% (19/173) pretransplant to $13 \%(23 / 173)$ at 1 year post-transplant, and $17 \%(29 / 170)$ at 5 years post-transplant, without significant differences between men and women.

Data of pre-transplant overweight/obesity were consistent with those of the Italian population (obesity, $10.2 \%$, overweight $31.7 \%$ ), [23] with slight differences in age and gender distribution (Fig. 2).

In pre-transplant assessment, eight patients were classified underweight according to WHO classification $(\mathrm{BMI}<18,5)$; two of these patients maintained mild thinness during the post-transplant monitoring, while the remaining patients entered the normal weight group during the post-transplant period.

Seventy-two percent of patients (124/173) were treated for post-transplant dyslipidemia: $60 \%$ patients $(104 / 173)$ were under treatment with statins (hypercholesterolemia) and $48 \%$ (83/173) with omega-3 fatty acids (hypertriglyceridemia). Patients treated for posttransplant dyslipidemia, as compared with non-treated patients, had significantly higher age at transplant 


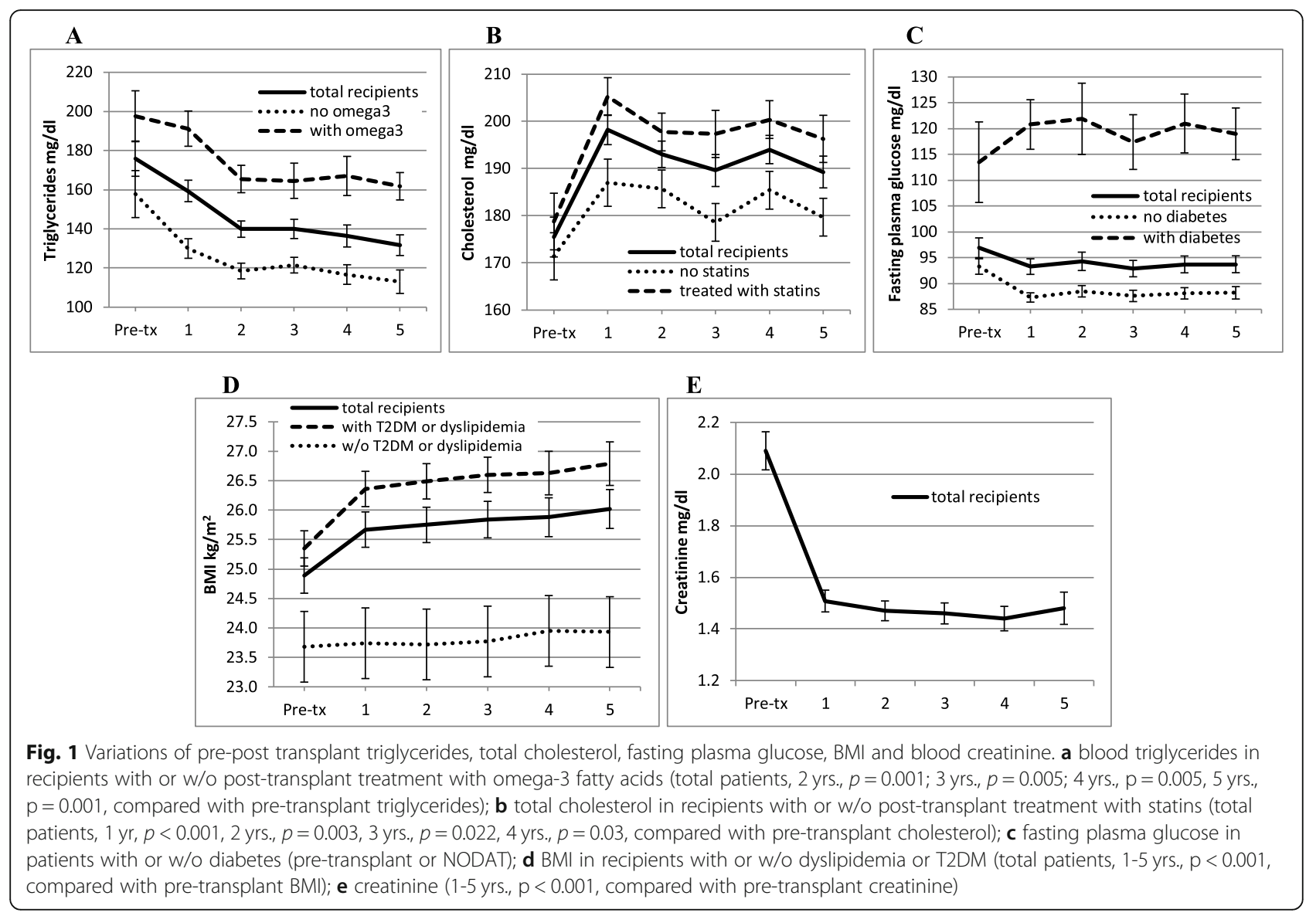

$(48.71 \pm 10.36$ vs. $41.47 \pm 9.46$ years, $p<0.001)$, fasting plasma glucose (pre-transplant: $99.73 \pm 26.85$ vs. $89.48 \pm$ $16.77 \mathrm{mg} / \mathrm{dL}, p=0.002$; after transplant, 3 yrs.: $95.40 \pm$ 22.12 vs. $86.24 \pm 13.82 \mathrm{mg} / \mathrm{dL}, p=0.017$ ) and BMI (pretransplant: $25.32 \pm 4.03$ vs. $23.72 \pm 4.02 \mathrm{~kg} / \mathrm{m}^{2}, p=0.037$; after transplant, 3 yrs.: $26.58 \pm 3.98$ vs. $23.88 \pm 3.67 \mathrm{~kg} /$ $\left.\mathrm{m}^{2}, \mathrm{p}<0.001\right)$.

In $5.2 \%$ of patients (9/173), type 1 diabetes mellitus (T1DM) was diagnosed before transplantation or was responsible for renal failure; $12.7 \%$ (22/173) had new-onset diabetes after transplantation (NODAT).

\section{Gene polymorphisms}

Distribution of HLA-G14bp ins/del genotypes and alleles in transplant recipients is reported in Table 2 and compared with those of the Italian population and of other studies in Caucasians.

As regards the assayed gene polymorphisms, no significant differences were observed between transplanted patients and controls (Supporting information Figure 6) and between genotypes according to characteristics of kidney transplant recipients described in Table 1 (gender, age at transplant, dialysis mode, time on dialysis, immunosuppressive therapy, cold ischemia time, acute rejection and organ loss, primary nephropathy).

\section{HLA-G14bp ins/del polymorphism and post-transplant risk factors}

A comparative analysis to evaluate the possible effect of genotypes on some of the most important clinical and biochemical parameters of recipients was performed.

HLA-G14bp ins/ins genotype frequencies were associated with presence of obesity at pre-transplant ( $p=$ 0.008, OR 3.88, CI 1.45-10.41) and at 3-5 years after transplant $(p=0.002$, OR 4.48, CI 1.76-11.41, $p=0.002$, OR 3.95, CI 1.67-9.34 and $p=0.028$, OR 2.68, CI 1.136.39, respectively).

Patients with HLA-G14bp ins/ins genotype had higher BMI after transplantation (Fig. 3): differences were statistically significant at 3 and 4 yrs., $(p=0.033$ and 0.044 , respectively), while $\mathrm{BMI}$ before the transplant was not significantly different among HLA-G14bp genotypes (Fig. 3b). No correlation was found between HLAG14bp ins/del genotypes and blood cholesterol, triglycerides, fasting plasma glucose, creatinine (Fig. 4).

By using a GLM analysis (repeated-measures ANOVA), a slight but significant effect of HLA-G14bp genotypes on BMI was observed (recessive model, ins/ ins vs. ins/del + del/del, $\mathrm{F}=3.95, p=0.049$ (Fig. 3b); no significant interaction between BMI and HLA-G14bp genotypes was detected, which means that BMI changed in 

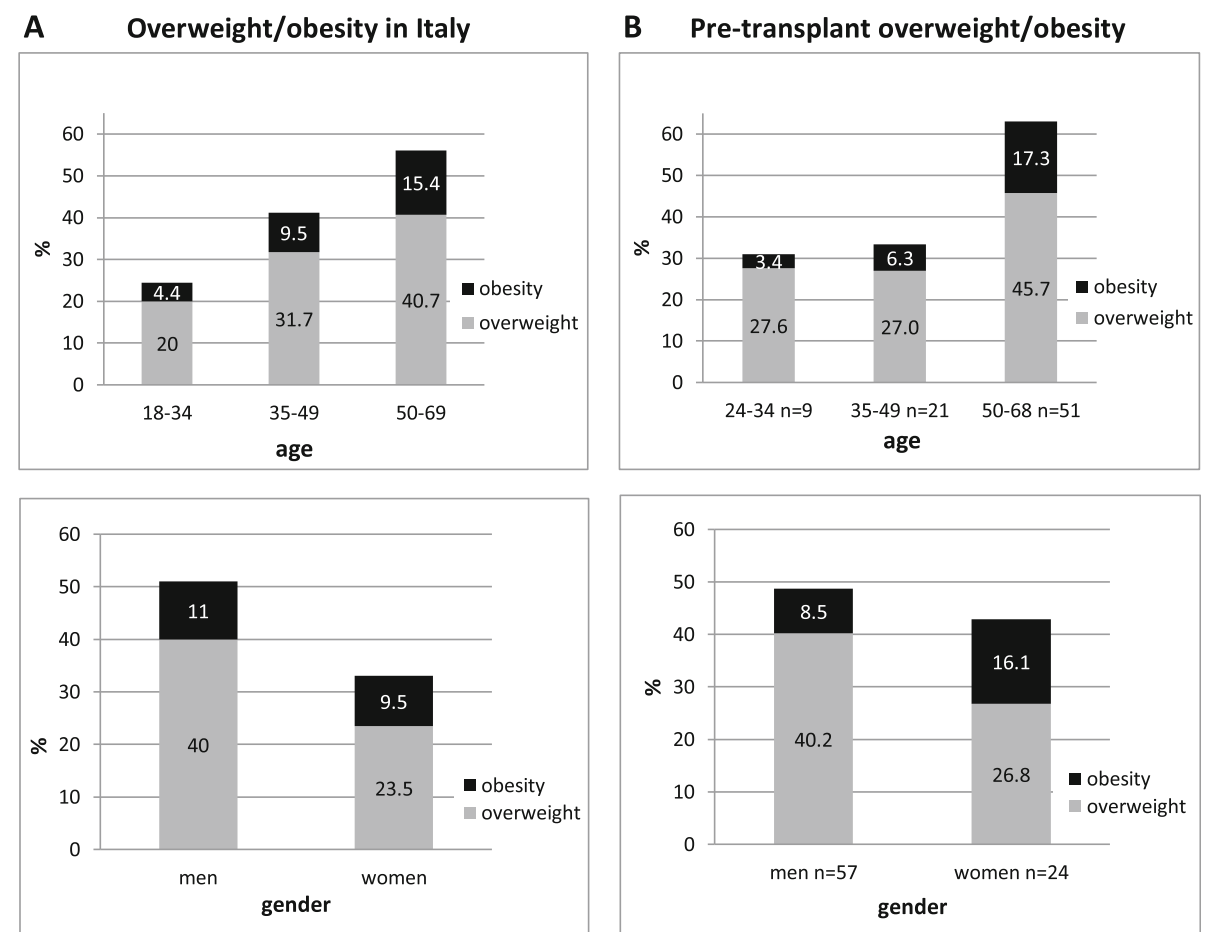

Fig. 2 a Overweight/obesity in Italian population [23]; b Overweight/obesity in pre-transplant recipients (present study)

time, but in the same way in the three groups based on HLA-G14bp genotypes.

Excluding pre-transplant obese recipients $(\mathrm{BMI}>30)$ from the analysis, it was possible to better evaluate effects of transplantation on weight gain: a significant interaction between BMI and HLA-G14bp genotypes was evidenced $(\mathrm{F}=4.45, p=0.007)$; paired $\mathrm{t}$-tests showed a substantial increase of BMI between one and the next years $(p<0.01)$ only in carriers of the ins/ins genotype, while carriers of other genotypes did not show further significant weight gain after the initial post-transplant increase (Fig. 3d). Differences between groups at each genotype are reported in Fig. 3.
These results were confirmed after adjustment for the effect of gender and age at transplant: a slight but significant effect of HLA-G14bp genotypes $(\mathrm{F}=4.87, p=$ $0.029)$ and age at transplant $(\mathrm{F}=12.00, p=0.001)$ on BMI was observed, with no interaction between HLAG14bp genotypes and BMI over time (Fig. 5a). When pre-transplant obese patients were excluded from the analysis, the significant interaction between HLA-G14bp and $\mathrm{BMI}$ was confirmed (recessive model, $\mathrm{F}=4.26, p=$ 0.009) (Fig. 5b).

Statistical significance was maintained when recipients with diabetes (NODAT, $n=22$, or pre-transplant, $n=7$ ) were excluded from the analyses (data not shown).

Table 2 HLA-G14bp genotypes/alleles in kidney transplant recipients and comparison between populations

\begin{tabular}{|c|c|c|c|c|c|c|c|c|}
\hline & \multicolumn{2}{|c|}{ Present study } & \multicolumn{4}{|c|}{ Italian population } & \multicolumn{2}{|c|}{ Brasilian population } \\
\hline & Recipients & Controls $^{a}$ & Controls $^{\mathrm{b}}$ & Controls ${ }^{c}$ & Recipients (Sardinia) ${ }^{d}$ & Controls (Sardinia) ${ }^{d}$ & Recipients $^{\mathrm{e}}$ & Controls $^{\mathrm{e}}$ \\
\hline & $(n=173)$ & $(n=118)$ & $(n=400)$ & $(n=102)$ & $(n=418)$ & $(n=371)$ & $(n=83)$ & $(n=97)$ \\
\hline Genotypes & $n(\%)$ & $n(\%)$ & $n(\%)$ & $n(\%)$ & $n(\%)$ & $n(\%)$ & $n(\%)$ & $n(\%)$ \\
\hline$-14 /-14,210 \mathrm{bp}$ & $42(24.3)$ & $40(33.9)$ & $124(31.0)$ & $36(35.3)$ & $139(33.5)$ & $119(32.2)$ & $21(25.3)$ & $32(33)$ \\
\hline$-14 /+14,210 / 224 b p$ & $93(53.7)$ & $62(52.5)$ & $216(54.0)$ & $47(46.1)$ & $198(47.4)$ & $178(47.9)$ & $37(44.6)$ & $49(51)$ \\
\hline$+14 /+14,224 b p$ & $38(22.0)$ & $16(13.6)$ & $60(15.0)$ & 19 (18.6) & $81(19.4)$ & $74(19.9)$ & $25(30.1)$ & $16(16)$ \\
\hline \multicolumn{9}{|l|}{ Alleles } \\
\hline$-14,210 \mathrm{bp}$ & $177(51.2)$ & $142(60.2)$ & $464(58.0)$ & $119(58.3)$ & $476(57.0)$ & $416(56.1)$ & 79 (47.6) & $113(58.2)$ \\
\hline$+14,224 b p$ & $169(48.8)$ & $94(39.8)$ & $336(42.0)$ & $85(41.7)$ & $360(43.0)$ & $326(43.9)$ & $87(52.4)$ & $81(41.8)$ \\
\hline
\end{tabular}


HLA-G14bp ins/del genotypes, total recipients

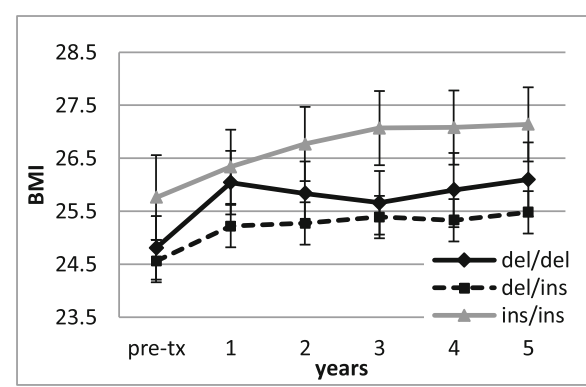

A

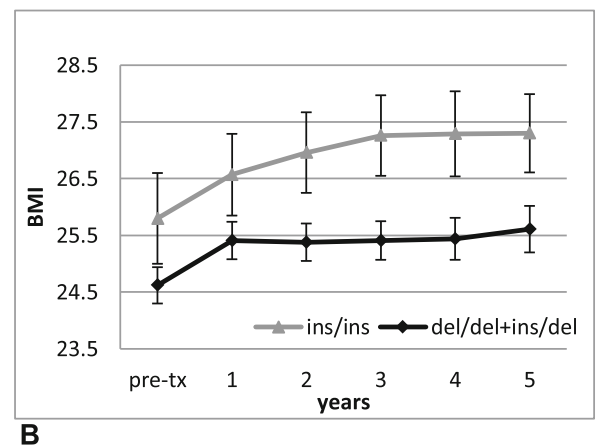

HLA-G14bp ins/del genotypes, excluded pre-transplant obese recipients

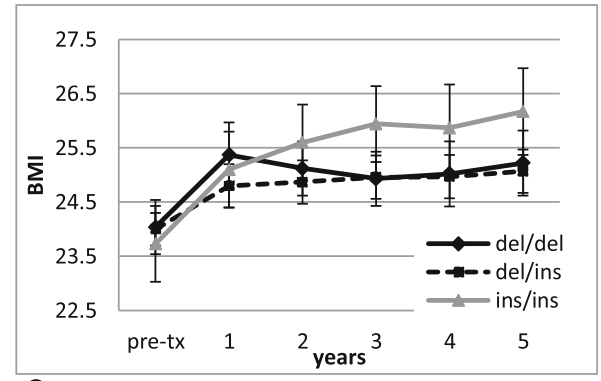

C

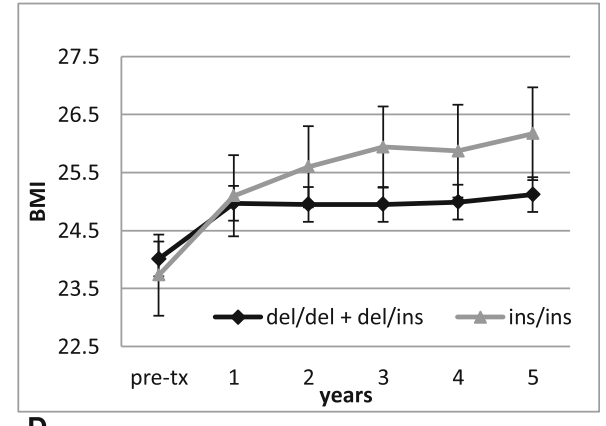

Fig. 3 Pre/post-transplant measurements of BMI $\left(\mathrm{kg} / \mathrm{m}^{2}\right)$ and HLA-G14bp ins/del genotypes in kidney transplant recipients: a and $\mathbf{b}$ : total recipients; $\mathbf{b}$ recessive model: significantly increased BMI in HLA-G14bp ins/ins, as compared with ins/del + del/del recipients, at 3 and 4 years ( $p=0.033$ and 0.044 , respectively); using repeated-measures ANOVA, it was observed a significant main effect of HLA-G14bp genotypes on BMI $(p=0.049$ ), with no significant interaction between BMI and HLA-G14bp genotypes; $\mathbf{c}$ and $\mathbf{d}$ : pre-post transplant BMI when pre-transplant obese patients (BMI > 30) were excluded from the analysis $(n=154)$; $\mathbf{d}$ recessive model: significant pre-post transplant weight gain in both ins/ins and ins/del + del/del carriers $(p<0.005)$ and significant interaction between BMI and HLA-G14bp genotypes $(F=4.45, p=0.007)$; after transplantation, only carriers of ins/ins genotype had significantly increased BMl between 1 to $2(p=0.01), 3(p=0.001), 4(p=0.008)$ and $5(p<0.001)$ years after transplant. Pre-tx $=$ pre-transplant

Cytokine gene polymorphisms and post-transplant risk factors IL-10 $(-1082 \mathrm{G}>\mathrm{A}),(-819 \mathrm{~T}>\mathrm{C}), \quad(-592 \mathrm{~A}>\mathrm{C}), \quad \mathrm{TGF}-\beta(+$ $869 \mathrm{~T}>\mathrm{C}),(+915 \mathrm{C}>\mathrm{G})$ IL-6 $(-174 \mathrm{G}>\mathrm{C}), \mathrm{TNF}-\alpha(-308 \mathrm{G}>$ A) and IL-18 $(-137 \mathrm{G}>\mathrm{C}),(-607 \mathrm{C}>\mathrm{A})$ cytokine polymorphisms were not correlated with the examined factors (BMI/obesity, blood cholesterol, triglycerides, fasting plasma glucose, creatinine) and their variations along the considered period after transplantation (Supporting information Figure 7: cytokine polymorphism and BMI; other variables: not shown).

As IL-10 and TGF- $\beta$ genotypes/haplotypes were previously associated with their release in vivo, analysis of results also included phenotypes, indicated as "high" (=high producers), "intermediate" (=intermediate producers) and "low" (=low producers), as previously reported [20]. Combinations of genotypes did not demonstrate significant effects on the evaluated parameters. The significantly increased frequency of IL-10-1082G/G genotype in HLA-G14bp ins/ins positive individuals, previously reported in healthy controls [17], was not confirmed in the present study. Neither effect of gender nor correlation with age at transplant were observed through genotypes.

\section{Discussion}

The research of genetic markers predictive of posttransplant complications and long-term graft survival is a frequent target in transplantation.

Here we explored the possible association of some functional polymorphisms of molecules involved in both tolerance and low grade inflammation with some parameters of increased risk for long-term complications in a group of kidney transplant recipients, as some cytokines and non classical HLA molecules involved in immunological mechanisms of allograft rejection could also interfere with cardiovascular and metabolic risk.

Monitoring some of the most common parameters up to 5 years post-transplant, an increase of BMI/obesity, fasting plasma glucose and cholesterol was registered, as expected, while both creatinine and triglycerides reduce over time. When these parameters were evaluated in association with cytokine genotypes and alleles, no predictive effects were found. Results showed a correlation of HLA-G14bp genotypes with BMI, which significantly increased in subsets of recipients carrying the ins/ins genotype. Considering overall patients, BMI changes in 

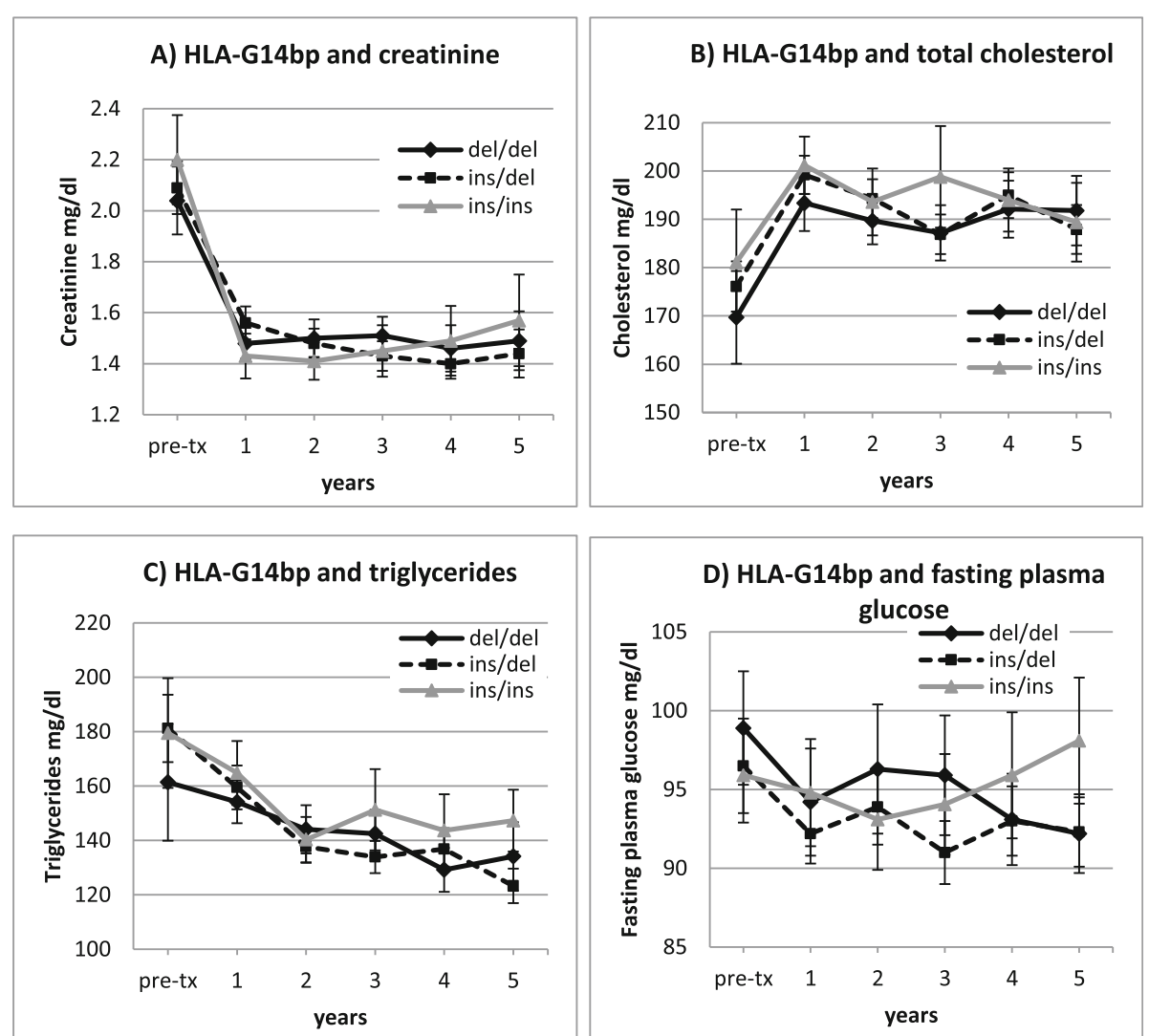

Fig. $4 \mathrm{HLA}-\mathrm{G} 14 \mathrm{bp}$ genotypes and pre/post-transplant variation of a) creatinine, b) total cholesterol, c) triglycerides and d) fasting plasma glucose in kidney transplant recipients $(p=n s)$

time, in the same way in the three groups based on HLA-G14bp, while a significant effect of HLA-G14bp ins/ins genotype on post-transplant weight gain was detected. Patients with HLA-G14bp ins/ins were more likely to develop obesity at 3 years after transplantation. No correlations were found with other parameters (blood cholesterol, triglycerides, fasting plasma glucose, creatinine). No significant associations of gene polymorphisms with posttransplant diabetes or rejection were found in this study, hence data on calcineurin inhibitors levels and specific anti rejection treatments have not been reported at this time. Effects of HLA-G14bp genotypes on post-transplant BMI were confirmed when considering only non-obese transplant candidates in the analysis, after controlling for age at transplant and gender. Effects of HLA-G14bp ins/ ins genotype on BMI, although limited, were significant and seemed independent of the presence of diabetes, metabolic syndrome and other risk factors associated with BMI increase and low-grade inflammation. Immunosuppressive regimens (tacrolimus or cyclosporine) did not affect this result.

Cytokine gene polymorphisms were not correlated with the examined variables and their variations during the considered period after transplantation. Neither effect of gender nor correlation with age at transplant was observed.

From the results of this study, HLA-G14bp ins/del polymorphism, previously involved in transplantation for its tolerogenic activity, seems to have a potential role in the development of obesity. This observation, carried out in transplant recipients, highlighted this potential link between HLA-G and obesity which, if confirmed (especially in long term evaluations), could also be of interest to other clinical contexts. Results of pre-transplant detections would not exclude an effect of HLA-G14bp polymorphism on obesity and inflammation associated with end stage renal disease. HLA-G is considered an anti-inflammatory factor that modulates immune cell responses [26]. Obesity and T2DM are characterized by low-grade inflammation [27], and a relationship seems to exist between HLA-G, obesity, and T2DM: in a study of HLA-G production in T2DM, sHLA-G was associated with higher BMI, cholesterol and blood pressure.

Recently, higher concentrations of sHLA-G have been observed in overweight-obese women during pregnancies, compared with healthy controls and with preeclamptic overweight/obese pregnancies [28]. Crosstalk between adipocytes, which could act as antigen presenting cells 


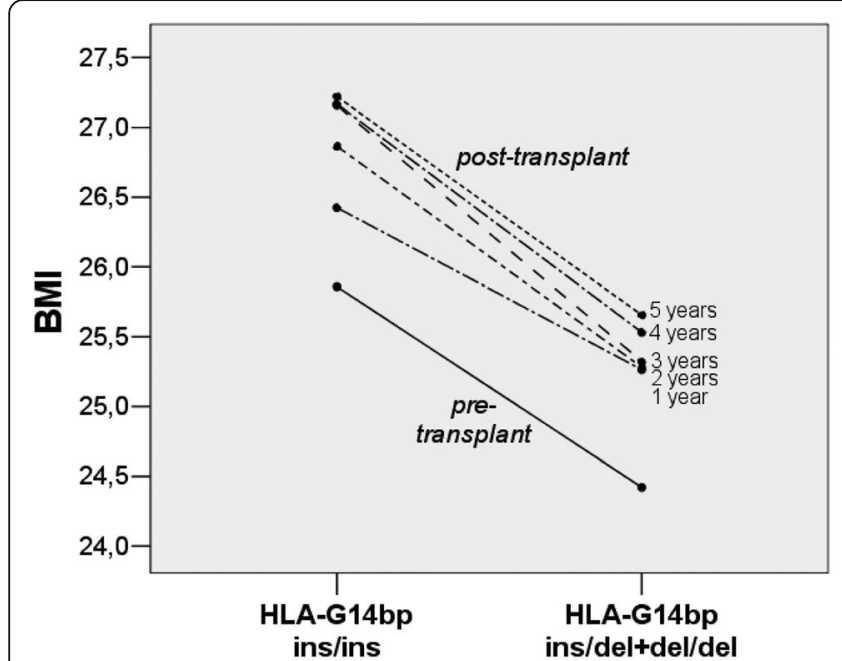

A

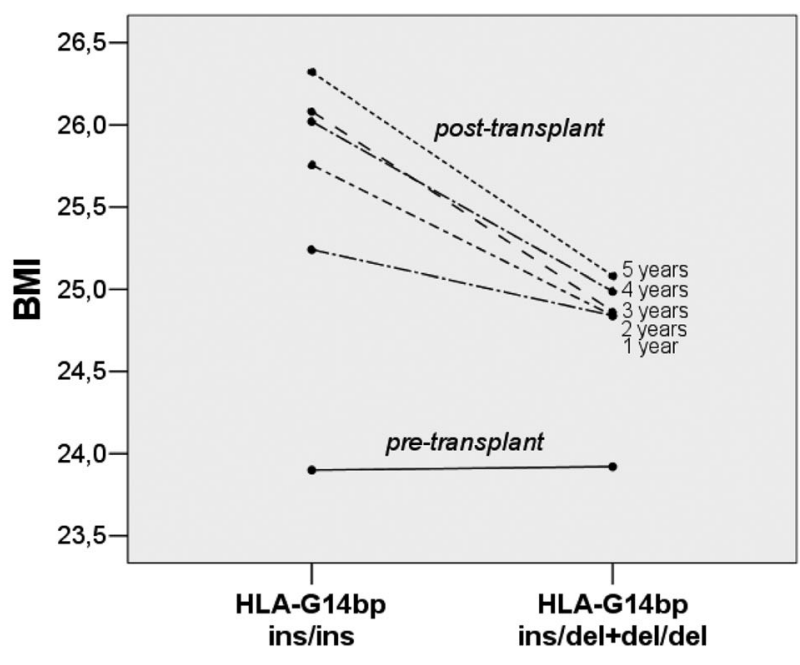

B

Fig. 5 Estimated marginal means of BMI and HLA-G14bp genotypes (recessive model), with gender and age at transplant as covariates; a total recipients: effect of HLA-G14bp ins/ins genotype ( $p=0.029)$ and age at transplant $(p=0.001)$ on BMI (pre-transplant, 1 to 5 years after transplant), with no interaction between HLA-G14bp genotypes and BMI over time (BMI was significantly increased between pre- to post-transplant in both ins/ins and ins/del + del/del carriers); $\mathbf{b}$ when pre-transplant obese recipients were excluded from the analysis, a significant interaction between HLA-G14bp genotypes and BMl over time was found ( $p=0.009)$

(APC), $\mathrm{T}$ cells and regulation of adipose tissue inflammation has been proposed and may involve cytokines and HLA-G expression [29].

From literature reviews on obesity-related genes, the role of pro-inflammatory cytokines (TNF- $\alpha$, IL-6, IL-1) is known, while that of anti-inflammatory molecules is less studied. Cytokine gene polymorphisms were also associated with obesity, metabolic syndrome, and cardiovascular risk [8-10, 30-41]. Nevertheless, we found no significant associations with cytokine gene polymorphism. In addition, the previously observed association of HLA-G14bp and IL-10-1082G/G (the high producer IL10-1082 genotype, most frequently found in individuals carrying the HLA-G14bp ins/ins [17]), was not present in transplanted patients.

Immunosuppressive protocols have changed over the years, with the replacement of azathioprine by mycophenolate mofetil (MMF) and the introduction of tacrolimus, monoclonal antibodies and mTORi. Therefore, the high-level immunosuppression achieved in the last years has made potential effects of gene polymorphisms less detectable, although they could affect the onset of complications, quality of life and overall graft survival in the long term. With these premises, what we could expect were small effects of genotypes that, in this particular condition, could highlight novel pathogenic mechanisms.

In the future, a deeper knowledge of diet-gene interaction [42] could produce novel genetically driven approaches in subsets of well-selected patients. Obesity is strongly affected by genetic components that, indeed, in physiological conditions, could be effectively counteracted by lifestyle and environmental interactions. Transplantation creates a particular condition in which a genetic substratum could act in synergy with external predisposing factors such as immunosuppressive therapy and inflammation. In this situation, it becomes particularly relevant to discover possible predisposing conditions. It should be considered that the effects of new biologic drugs can be modified by genetic polymorphisms. For example, the fusion protein cytotoxic $\mathrm{T}$ lymphocyte antigen (CTLA)4-Ig, introduced for prevention of rejection, mainly exerts its tolerogenic function through sHLA-G release [43].

\section{Conclusions}

We analyzed associations of some gene polymorphisms with pre/post-transplant variations of the main risk factors for metabolic/cardiovascular diseases, like excess body weight, increased blood lipids and fasting plasma glucose, and we found out a potential relationship between posttransplant weight gain and HLA-G14bpins gene variant in kidney transplant recipients. The particular condition of newly transplanted patients (the start of immunosuppressive therapy and a careful post-transplant monitoring that includes metabolic parameters affected by this treatment) have allowed to uncover this potentially interesting association. This novel association could add new elements to the study of obesity susceptibility factors and to the knowledge of the role and functions of HLA-G molecules in diseases and transplantation. 


\section{Supplementary information}

Supplementary information accompanies this paper at https://doi.org/10. 1186/s12882-020-01752-6.

Additional file 1. Supporting information - Figure6 Cytokine genotypes, alleles and haplotypes in kidney transplant recipients and controls.

Additional file 2. Supporting information - Figure7 Cytokine genotypes and pre/post-transplant BMI in kidney transplant recipients.

\section{Abbreviations}

APC: Antigen presenting cells; BMl: Body mass index; bp: Base pair; CD25: Cluster of differentiation 25; Cl: Confidence interval; CTLA-4: Cytotoxic T-Lymphocyte Antigen 4; del: Deletion; DNA: Deoxyribonucleic acid; GLM: General linear model; HLA: Human leukocyte antigen; IL: Interleukin ins: Insertion; LPS: Lipopolysaccharides; MMF: Mycophenolate mofetil; mRNA: Messenger ribonucleic acid; mTORi: Mammalian target of rapamycin inhibitors; NODAT: New onset diabetes after transplantation; OR: Odds ratio PBMC: Peripheral blood mononuclear cells; PCR: Polymerase chain reaction; SSP: Sequence specific primers; T1DM: Type 1 diabetes mellitus; T2DM: Type 2 diabetes mellitus; TGF: Transforming growth factor; TNF: Tumor necrosis factor; WHO: World health organization

\section{Acknowledgements}

The authors thank the staff of the Transplant Unit for their collaboration.

\section{Authors' contributions}

DP participated in research design, data analysis and writing the manuscript; AC and PS participated in sample collection, data acquisition and genotyping; DM, KC, SI, QL, and FP participated in research design and performed clinical monitoring and clinical data management of recipients. All authors read and approved the final manuscript.

\section{Funding}

This work was supported by Carispaq Foundation, L'Aquila, Italy. This organization had no role of the in the design of the study, collection, analysis, interpretation of data and in writing the manuscript.

\section{Availability of data and materials}

The data that support the findings of this study are available within the article and its supplementary information files or from the corresponding author on reasonable request.

\section{Ethics approval and consent to participate}

A statement on ethics approval and consent is included in Methods section. Written informed consent was obtained from all subjects and the study was approved by the local ethics committee of the Azienda Sanitaria Locale, ASL L'Aquila, study n. 50/2008. Blood samples were obtained via the Unit of "General Surgery and Transplantation" of S. Salvatore Hospital of L'Aquila; no organs/tissues were obtained from prisoners.

\section{Consent for publication}

Not applicable.

\section{Competing interests}

The authors declare that they have no competing interests.

\section{Author details}

${ }^{1}$ National Research Council (CNR) - Institute of Translational Pharmacology (IFT), Via Carducci, 32, 67100 L'Aquila, Italy. ${ }^{2}$ Regional Center for Organ Transplantation (CRT), S. Salvatore Hospital, L'Aquila, Italy. ${ }^{3}$ General Surgery and Organ Transplantation, S. Salvatore Hospital, L'Aquila, Italy. ${ }^{4}$ Pôle de chirurgie expérimentale et transplantation, Institut de recherche expérimentale et clinique, Université catholique de Louvain, Brussels, Belgium. ${ }^{5}$ Department of Biotechnological and Applied Clinical Sciences, University of L'Aquila, L'Aquila, Italy. "Transplant Unit, University "La Sapienza", Rome, Italy.
Received: 30 October 2019 Accepted: 28 February 2020

Published online: 30 March 2020

\section{References}

1. Badiou S, Cristol JP, Mourad G. Dyslipidemia following kidney transplantation: diagnosis and treatment. Curr Diab Rep. 2009;9:305-11.

2. Curran SP, Famure O, Li Y, Kim SJ. Increased recipient body mass index is associated with acute rejection and other adverse outcomes after kidney transplantation. Transplantation. 2014;97:64-70.

3. Pischon T, Sharma AM. Obesity as a risk factor in renal transplant patients. Nephrol Dial Transplant. 2001;16:14-7.

4. Iyer A, Fairlie DP, Prins JB, Hammock BD, Brown L. Inflammatory lipid mediators in adipocyte function and obesity. Nat Rev Endocrinol. 2010:6:7182.

5. Ilavska S, Horvathova M, Szabová M, Nemessányi T, Jahnová E, Tulinská J, et al. Association between the human immune response and body mass index. Hum Immunol. 2012;73:480-5.

6. Karlsson EA, Beck MA. The burden of obesity on infectious disease. Exp Biol Med. 2010;235:1412-24.

7. Hersoug LG, Linneberg A. The link between the epidemics of obesity and allergic diseases: does obesity induce decreased immune tolerance? Allergy. 2007:62:1205-13.

8. Bamoulid J, Courivaud C, Deschamps M, Gaugler B, Tiberghien P, Chalopin $\mathrm{JM}$, et al. The Interleukin-6 gene promoter polymorphism -174 and atherosclerotic events in overweight transplanted patients. J Transp Secur. 2011:2011:803429.

9. Thompson SR, Sanders J, Stephens JW, Miller GJ, Humphries SE. A common interleukin 18 haplotype is associated with higher body mass index in subjects with diabetes and coronary heart disease. Metabolism. 2007;56: 662-9.

10. Kim HL, Cho SO, Kim SY, Kim SH, Chung WS, Chung SH. Association of Interleukin-18 gene polymorphism with body mass index in women. Reprod Biol Endocrinol. 2012;10:31-6.

11. Hviid TV, Rizzo R, Christiansen OB, Melchiorri L, Lindhard A, Baricordi OR HLA-G and IL-10 in serum in relation to HLA-G genotype and polymorphisms. Immunogenetics. 2004;56:135-41.

12. Rouas-Freiss N, LeMaoult J, Moreau P, Dausset J, Carosella ED. HLA-G in transplantation: a relevant molecule for inhibition of graft rejection? Am J Transpl. 2003:3:11-6.

13. Crispim JC, Mendes-Junior CT, Wastowski IJ, Costa R, Castelli EC, Saber LT, Donadi EA. Frequency of insertion/deletion polymorphism in exon 8 of HLA-G and kidney allograft outcome. Tissue Antigens. 2008;71:35-41.

14. Littera R, Piredda G, Pani A, Frongia M, Onano B, Michittu MB, et al. Role of human leukocyte antigen-G 14-base pair polymorphism in kidney transplantation outcomes. J Nephrol. 2013;26:1170-8.

15. Misra MK, Prakash S, Kapoor R, Pandey SK, Sharma RK, Agrawal S. Association of HLA-G promoter and 14-Bp insertion-deletion variants with acute allograft rejection and end-stage renal disease. Tissue Antigens. 2013; $82: 317-26$.

16. Zilinska Z, Bandzuchova H, Chrastina M, Trebatický B, Breza JS, Handzušová $M$, et al. Expression of HLA-G transcripts in graft biopsy samples of renal transplant recipients. Transpl Immunol. 2015:33:159-65.

17. Rizzo R, Hviid TV, Stignani M, Balboni A, Grappa MT, Melchiorri L, et al. The HLA-G genotype is associated with IL-10 levels in activated PBMCs. Immunogenetics. 2005;57:172-81.

18. Waters $S$, Lee $S$, Affandi JS, Irish A, Price P. The effect of genetic variants affecting NK function on cardiovascular health and the burden of CMV. Hum Immunology. 2017;78:747-51.

19. Hviid TV, Hylenius S, Hoegh AM, Kruse C, Christiansen OB. HLA-G polymorphisms in couples with recurrent spontaneous abortions. Tissue Antigens. 2002;60:122-32.

20. Mytilineos J, Laux G, Opelz G. Relevance of IL10, TGFbeta1, TNFalpha, and IL4Ralpha gene polymorphisms in kidney transplantation: a collaborative transplant study report. Am J Transplant. 2004;4:1684-90.

21. Excoffier $L$, Lischer HE. Arlequin suite Ver 3.5: a new series of programs to perform population genetics analyses under Linux and windows. Mol Ecol Resour. 2010:10:564-7.

22. Report of a Who Expert Committee. Physical Status: The Use and Interpretation of Anthropometry. World Heal Organ Tech Rep Ser. 1995;854: $1-452$. 
23. Baldissera S, Ferrante G, Quarchioni E, Minardi V, Possenti V, Carrozzi G, et al. Field substitution of nonresponders can maintain sample size and structure without altering survey estimates-the experience of the Italian behavioral risk factors surveillance system (PASSI). Ann Epidemiol. 2014; 24:241-5.

24. Fabris $A$, Segat $L$, Catamo $E$, Morgutti M, Vendramin A, Crovella S. HLA-G 14 bp deletion/insertion polymorphism in celiac disease. Am J Gastroenterol. 2011;106:139-44.

25. Sizzano F, Testi M, Zito L, Crocchiolo R, Troiano M, Mazzi B, et al. Genotypes and haplotypes in the 3' Untranslated region of the HLA-G gene and their association with clinical outcome of hematopoietic stem cell transplantation for Beta-thalassemia. Tissue Antigens. 2012;79: 326-32.

26. Rizzo R, Bortolotti D, Baricordi OR, Fainardi E. New insights into HLA-G and inflammatory diseases, Inflamm. Allergy Drug Targets. 2012;11: 448-63.

27. Solini A, Muscelli E, Stignani M, Santini E, Rossi C, et al. Soluble human leukocyte antigen-G expression and glucose tolerance in subjects with different degrees of adiposity. J Clin Endocrinol Metab. 2010;95:3342-6.

28. Beneventi F, Locatelli E, De Amici M, Martinetti M, Spinillo A. Soluble HLA-G concentrations in obese women during pregnancy and in cord blood. J Reprod Immunol. 2017;119:31-7.

29. Poloni A, Maurizi G, Ciarlantini M, Medici M, Mattiucci D, Mancini S, et al. Interaction between human mature adipocytes and lymphocytes induces T-cell proliferation. Cytotherapy. 2015;17:1292-301.

30. La Manna G, Cappuccilli ML, Cianciolo G, Conte D, Comai G, Carretta E, et al. Cardiovascular disease in kidney transplant recipients: the prognostic value of inflammatory cytokine genotypes. Transplantation. 2010;89:1001-8.

31. Kubaszek A, Pihlajamaki J, Komarovski V, Lindi V, Lindström J, Eriksson J, et al. Promoter polymorphisms of the TNF-alpha (G-308A) and IL-6 (C$174 \mathrm{G})$ genes predict the conversion from impaired glucose tolerance to type 2 diabetes: the Finnish diabetes prevention study. Diabetes. 2003; 52:1872-6.

32. Mohlig M, Boeing $H$, Spranger J, Osterhoff M, Kroke A, Fisher E, et al. Body mass index and C-174G Interleukin-6 promoter polymorphism interact in predicting type 2 diabetes. J Clin Endocrinol Metab. 2004;89:1885-90.

33. Klipstein-Grobusch K, Mohlig M, Spranger J, Hoffmann K, Rodrigues FU, Sharma AM, et al. Interleukin-6 G.-174G>C Promoter Polymorphism Is Associated with Obesity in the Epic-Potsdam Study. Obesity. 2006;14:14-8.

34. Zirlik A, Bavendiek U, Libby P, MacFarlane L, Gerdes N, Jagielska J, et al. TRAF- $1,-2,-3,-5$, and -6 are induced in atherosclerotic plaques and differentially mediate Proinflammatory functions of CD40L in endothelial cells. Arter Thromb Vasc Biol. 2007;27:1101-7.

35. Esposito K, Pontillo A, Giugliano F, Giugliano G, Marfella R, Nicoletti G, et al. Association of low Interleukin-10 levels with the metabolic syndrome in obese women. J Clin Endocrinol Metab. 2003:88:1055-8.

36. Riikola A, Sipila K, Kahonen M, Jula A, Nieminen MS, Moilanen L, et al. Interleukin-6 promoter polymorphism and cardiovascular risk factors: the health 2000 survey. Atherosclerosis. 2009;207:466-70.

37. Goyenechea E, Parra D, Martinez JA. Impact of Interleukin 6-174G>C Polymorphism on Obesity-Related Metabolic Disorders in People with Excess in Body Weight. Metabolism. 2007;56:1643-8.

38. Tiret L, Godefroy T, Lubos E, Nicaud V, Tregouet DA, Barbaux S, et al. Genetic analysis of the Interleukin-18 system highlights the role of the Interleukin-18 gene in cardiovascular disease. Circulation. 2005;112:643-50.

39. Hernesniemi JA, Karhunen PJ, Oksala N, Kähönen M, Levula M, Rontu R, et al. Interleukin 18 gene promoter polymorphism: a link between hypertension and pre-hospital sudden cardiac death: the Helsinki sudden death study. Eur Heart J. 2009;30:2939-46.

40. Evans J, Collins M, Jennings C, van der Merwe L, Söderström I, Olsson T, et al. The Association of Interleukin-18 genotype and serum levels with metabolic risk factors for cardiovascular disease. Eur J Endocrinol. 2007;157: 633-40.

41. Heiskanen M, Kahonen M, Hurme M, Lehtimäki T, Mononen N, Juonala M, et al. Polymorphism in the IL 10 promoter region and early markers of atherosclerosis: the cardiovascular risk in young Finns study. Atherosclerosis. 2010;208:190-6

42. Barth SW, Koch TC, Watzl B, Dietrich H, Will F, Bub A. Moderate effects of apple juice consumption on obesity-related markers in obese men: impact of diet-gene interaction on body fat content. Eur J Nutr. 2012;51:841-50.
43. Bahri R, Naji A, Menier C, Charpentier B, Carosella ED, Rouas-Freiss N, et al. Dendritic cells secrete the immunosuppressive HLA-G molecule upon CTLA4-Ig treatment: implication in human renal transplant acceptance. J Immunol. 2009;183:7054-62.

\section{Publisher's Note}

Springer Nature remains neutral with regard to jurisdictional claims in published maps and institutional affiliations.
Ready to submit your research? Choose BMC and benefit from:

- fast, convenient online submission

- thorough peer review by experienced researchers in your field

- rapid publication on acceptance

- support for research data, including large and complex data types

- gold Open Access which fosters wider collaboration and increased citations

- maximum visibility for your research: over $100 \mathrm{M}$ website views per year

At BMC, research is always in progress.

Learn more biomedcentral.com/submissions 